\title{
Preparation and Characterization of Regenerated Cellulose Biocomposite Film Filled with Calcium Carbonate by in situ Precipitation
}

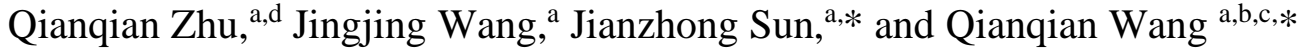 \\ The application of cellulose hybrid biocomposites filled with calcium \\ carbonate has attracted wide attention in packaging and other fields in \\ recent years. In this study, regenerated cellulose $(R C)$ films filled with \\ calcium carbonate were successfully prepared by dissolution, \\ regeneration, and in situ precipitation of $\mathrm{CaCO}_{3}$. The optical, mechanical, \\ physical, and chemical properties of biocomposites were examined by UV- \\ visible spectroscopy, tensile testing, scanning electron microscopy (SEM), \\ X-ray diffraction (XRD), Fourier transform infrared spectroscopy (FTIR), \\ and thermogravimetric analyses (TGA). The results showed that RC films \\ with different $\mathrm{CaCO}_{3}$ contents exhibited good flexibility, optical properties, \\ mechanical strength, and thermal stability. The RC biocomposite filled with \\ calcium carbonate showed a tensile strength of $84.7 \pm 1.5 \mathrm{MPa}$ at optimum \\ conditions. These $\mathrm{RC}$ biocomposites filled with $\mathrm{CaCO}_{3}$ may find \\ application in packaging.
}

Keywords: Organic-inorganic hybrid biocomposite; Calcium carbonate; Mechanical property; Characterization

Contact information: a: Biofuels Institute, School of the Environment and Safety Engineering, Jiangsu University, Zhenjiang 212013 China; b: State Key Laboratory of Pulp and Paper Engineering, South China University of Technology, Guangzhou 510640 China; $c$ : Institute of Chemical Industry of Forest Products, Chinese Academy of Forestry, Key Laboratory of Biomass Energy and Material, Jiangsu Province, Nanjing 210042, China; d: Analysis and Testing Center, Jiangsu University, Zhenjiang, 212013 PR China; *Corresponding authors: jzsun1002@ujs.edu.cn; qianqian.wz@gmail.com

\section{INTRODUCTION}

As a renewable, biodegradable, and biocompatible polymer, cellulose offers tremendous opportunities for different products, including paper and paperboard, textiles, and drug tablets (Wang et al. 2018, 2019; Zhu et al. 2020a,b). Although it is generally considered as abundant and low-cost biomass, the price of the cellulose pulp is still high compared with inorganic fillers (Laukala et al. 2017; Xu et al. 2017). Inorganic fillers, such as calcium carbonate, are used in nearly every paper and paperboard product to save virgin pulp, dry energy, and production costs. The addition of $\mathrm{CaCO}_{3}$ also brings some special properties for the final paper products, such as optical, physical, mechanical, and surface property improvements (Cheng et al. 2016; Seo et al. 2017; Choi et al. 2018). Ground and precipitated calcium carbonate fillers (GCC and PCC, respectively) are normally added to the cellulose pulp suspension before the formation of paper or paperboard. In-situ $\mathrm{CaCO}_{3}$ formation can be also applied with the aim of maximizing filler retention (Ciobanu et al. 2010; Seo et al. 2017). Biomimetic design and synthesis of nanocellulose- $\mathrm{CaCO}_{3}$ hybrid materials to new green materials are also in the spotlight (Saito et al. 2014; Nakao et al. 2019). Biodegradable regenerated cellulose (RC) films can be prepared by coagulation and 
regeneration from various cellulose solvents, including ionic liquids (ILs), N,N-dimethylacetamide/lithium chloride (DMA/LiCl), and $\mathrm{NaOH} /$ urea solution (Sathitsuksanoh et al. 2013; Wang et al. 2016). The obtained RC films showed much better properties, such as better air oxygen permeability, thermal stability, and lower thermal expansion coefficient, compared to petroleum-based plastic substrates. The RC films show great potential in packaging and other applications. To further improve the performance of cellulose films, biodegradable cellulose copolymer films with organic fillers/coatings were prepared (Delhom et al. 2010; Yang et al. 2014).

However, the research on in situ precipitation of calcium carbonate on RC films is limited. The precipitation behavior of $\mathrm{CaCO}_{3}$ on $\mathrm{RC}$ film from the ionic liquid (1-butyl-3methylimidazolium chloride, BMIMCL) in ethanol-water was presented by Xiao et al. (2011), while the mineralization of $\mathrm{CaCO}_{3}$ on $\mathrm{RC}$ film from $\mathrm{DMA} / \mathrm{LiCl}$ solvent was investigated by Rauch et al. (2012). The mechanism for in situ calcium carbonate precipitation in RC hydrogel was proposed by Rauch et al. (2012). It is well known that cellulose surfaces are negatively charged, thus leading to accumulation of $\mathrm{Ca}^{2+}$ ions in the charged surface and inducing the nucleation, aggregation, and crystallization. The crystallization of calcium carbonate is limited to the specific nucleation sites, because of the complexation of the $\mathrm{Ca}^{2+}$ ions and negatively charged groups in cellulose fibers. The nanocrystals then grow larger and the small aggregates are formed, and these are interconnected by the cellulose fibers. Subsequently, these crystals that are strongly attached to the cellulose network become assembled into large aggregates. To the authors' best knowledge, there is no report on the in situ precipitation of calcium carbonate on regenerated cellulose made from $\mathrm{NaOH}$ /urea solution. Little is known about the effects of calcium carbonate when incorporated into the $\mathrm{RC}$ matrix by in situ precipitation. As an inorganic filler, the incorporation of calcium carbonate could lead to an improvement in biocomposite film properties and cost reduction. Furthermore, the precise mechanism for in situ $\mathrm{CaCO}_{3}$ precipitation on RC films is still ambiguous.

The properties of a biocomposite made of $\mathrm{RC}$ by $\mathrm{NaOH} / \mathrm{urea}$ solution and in situ calcium carbonate precipitation remains to be elucidated. In this study, strong and translucent RC biocomposite films filled with calcium carbonate were developed. The method involved the coagulation and regeneration of cellulose films and in situ calcium carbonate precipitation in the regenerated hydrogel. The properties of $\mathrm{RC}$ and calcium carbonate biocomposite films were evaluated. The starting materials were also characterized. The effects of the precursor concentration on the properties of the biocomposite films are discussed.

\section{EXPERIMENTAL}

\section{Materials and Chemicals}

Cellulose powder from cotton linters was purchased from Hubei Chemical Fiber Group Co., Ltd. (Xiangyang, China) and milled to pass through a 40-mesh sieve with a laboratory grinder (FZ102; Tianjin Taipingyuanda Instrument Co., Ltd., Tianjin, China). The molecular weight of cellulose was estimated to be $1.07 \times 10^{5} \mathrm{~kg} / \mathrm{mol}$ by using a viscometer. Calcium chloride and sodium carbonate were obtained from Sigma-Aldrich (Shanghai, China). Sodium hydroxide, urea, and sulfuric acid were obtained from Sinopharm Chemical Reagent Co., Ltd. (Shanghai, China) and used as received.

Zhu et al. (2020). "Regenerated cellulose- $\mathrm{CaCO}_{3}$ films," BioResources 15(4), 7893-7905. 7894 


\section{Cellulose Dissolution with $\mathrm{NaOH} /$ Urea Solution}

Cellulose powder was dried at $80^{\circ} \mathrm{C}$ for $6 \mathrm{~h}$ in a vacuum drying oven (BPZ-6033; Shanghai Yiheng Scientific Instrument Co., Ltd., Shanghai, China). Cellulose solvent, $\mathrm{NaOH} /$ urea solution, was made by mixing $\mathrm{NaOH}$, urea, and $\mathrm{H}_{2} \mathrm{O}$ at a weight ratio of $7: 12$ : 81. The $\mathrm{NaOH} /$ urea solution was precooled to $-12{ }^{\circ} \mathrm{C}$ in a refrigerator (SC-276; Haier Company Limited, Qingdao, China). A $4.0 \mathrm{wt} \%$ suspension of cellulose powder in $\mathrm{NaOH} /$ urea solution was made by dissolving $4 \mathrm{~g}$ of cotton linters powder in $96 \mathrm{~g}$ $\mathrm{NaOH} /$ urea solution. The suspension was vigorously stirred for $5 \mathrm{~min}$. The air bubbles and undissolved cellulose aggregates were removed by centrifuge with an Avanti J-E Centrifuge (JA-10 rotor; Beckman Coulter, Brea, CA, USA) at $8000 \mathrm{rpm}$ for $10 \mathrm{~min}$. A transparent and viscous cellulose solution was obtained.

\section{Preparation of RC Film via Solution Casting}

Cellulose solution was poured onto a glass plate and cast with a glass rod. The glass rod wrapped with a certain thickness tape evenly distributed the cellulose solution. A layer of hydrogel with thickness proportional to the tape thickness was formed. The glass plate with the cellulose hydrogel was gently placed into a coagulation bath $\left(1 \mathrm{~L}_{5} \% \mathrm{H}_{2} \mathrm{SO}_{4}\right)$ until the film was detached from the plate, which took approximately $5 \mathrm{~min}$. The detached film was carefully washed with deionized water (DI) until the $\mathrm{pH}$ of water did not change. The film was then air-dried on a stainless steel plate surface. The obtained film was labeled as $\mathrm{RC}$ and kept for further analysis.

\section{Preparation of RC Film with in-situ $\mathrm{CaCO}_{3}$ Precipitation}

In-situ precipitation of calcium carbonate into RC film was performed by sequentially impregnating calcium chloride and sodium carbonate in the presence of RC film. In detail, the RC hydrogel film was firstly immersed in calcium chloride solution at concentrations of $0.2,0.5,0.8$, or $1.0 \mathrm{~mol} / \mathrm{L}$ for $24 \mathrm{~h}$. Then, the hydrogel film was immersed in a sodium carbonate solution of the same concentration as the calcium chloride solution for another $24 \mathrm{~h}$. Calcium carbonate can be obtained through the double-exchange reaction between sodium carbonate and calcium chloride. The $\mathrm{RC}$ with in-situ $\mathrm{CaCO}_{3}$ precipitation was gently washed with DI water and air-dried. The films were labeled as RC-C02, RCC05, RC-C08, and RC-C10, depending on the concentration of the solution for $\mathrm{CaCO}_{3}$ formation.

\section{Methods}

Light transmittance and optical properties of RC were determined by a conventional UV-visible (UV-vis) spectrometer (DU800; Beckman Coulter, Brea, CA, USA) in the range of 200 to $800 \mathrm{~nm}$ with air as the background. A wavelength of $600 \mathrm{~nm}$ was used to determine the film transmittance. Each sample was scanned three times. The tensile strength of RC films was measured with a tensile tester (Model YG026MB; Fangyuan Instrument Co., Ltd., Wenzhou, China) with a $1000-\mathrm{N}$ load cell at a speed of $5 \mathrm{~mm} / \mathrm{min}$ at $26{ }^{\circ} \mathrm{C}$ and $65 \%$ relative humidity. At least five specimens were measured for each sample, and the average value was reported. Surface and cross-section morphologies of RC films were determined using an S-3400N scanning electron microscope (SEM) equipped with an EDAX energy-dispersive X-ray (EDAX LLC, Mahwah, NJ, USA). The specimens were carefully mounted on an SEM sample stub with double-sided sticky carbon conductive tape and then spray coated with gold (MSP-1S; Shinkku VD, Tokyo, Japan) for $60 \mathrm{~s}$ in a vacuum chamber before analysis. The energy-dispersive X-ray spectrum was conducted to confirm 
the presence of $\mathrm{CaCO}_{3}$ in $\mathrm{RC}$ film. The X-ray diffraction (XRD) spectra of RC films were analyzed using a D8 Advance diffractometer with a CuKa source (Bruker AXS, Billerica, MA, USA). Scans with an angle range of $2 \theta=10$ to $60^{\circ}$ were collected with a speed of $2 \%$ min. Fourier transform infrared spectroscopy (FTIR) spectra were determined using a Nexus 470 FTIR spectrometer (Thermo Electron Corporation, Waltham, MA, USA). The $\mathrm{RC}$ film was first dried and milled into fine powder in liquid nitrogen. Samples were then mixed with $\mathrm{KBr}$ and pelletized into a transparent pallet, and their spectra in the range of 4000 to $500 \mathrm{~cm}^{-1}$ with a resolution of $4 \mathrm{~cm}^{-1}$ were recorded. Thermogravimetric analyses (TGA) were conducted to examine the degradation behavior of the $\mathrm{RC}$ at various $\mathrm{CaCO}_{3}$ precipitation using a thermogravimetric analyzer (TGA 4000; Perkin Elmer, Waltham, MA, USA). Approximately $5 \mathrm{mg}$ specimens were heated at $10{ }^{\circ} \mathrm{C} / \mathrm{min}$ from $30{ }^{\circ} \mathrm{C}$ to $800{ }^{\circ} \mathrm{C}$ in a nitrogen atmosphere $(50 \mathrm{~mL} / \mathrm{min})$.

\section{RESULTS AND DISCUSSION}

\section{Optical Transmittance and Tensile Strength of $\mathrm{RC}-\mathrm{CaCO}_{3}$ Films}

The $\mathrm{RC}$ biocomposite films prepared by solution casting and in situ $\mathrm{CaCO}_{3}$ precipitation had good flexibility. Figure 1a to 1e show optical images of the RC films with $\mathrm{CaCO}_{3}$ precipitation at concentrations of $0,0.2,0.5,0.8$, and $1.0 \mathrm{~mol} / \mathrm{L}$ for precursor solutions. The films prepared under different conditions showed obvious differences.
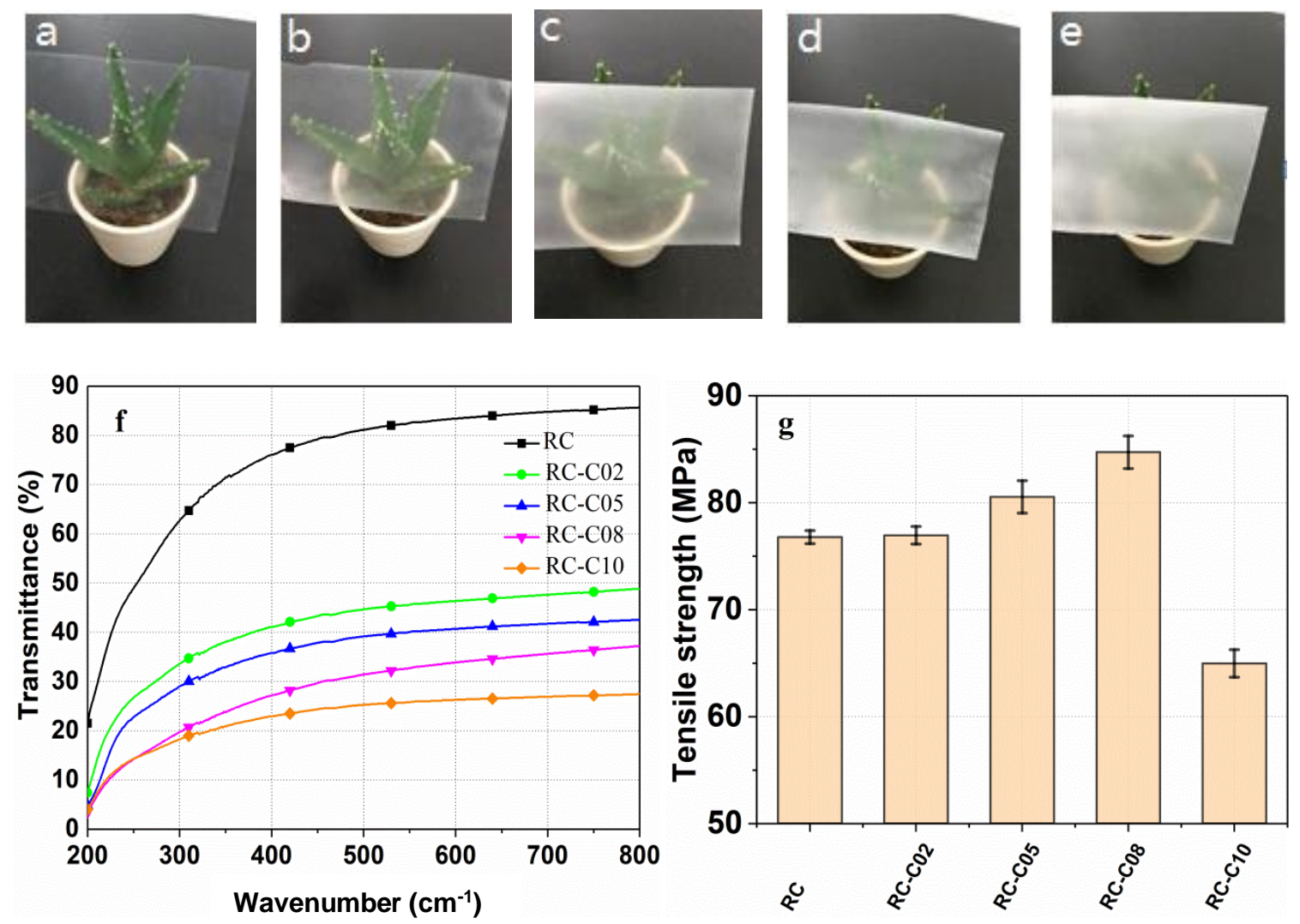

Fig. 1. Visual observation of (a) RC; (b) RC-C02; (c) RC-C05; (d) RC-C08; and (e) RC-C10 e films (thickness $=35 \mu \mathrm{m}$ ); (f) UV-Vis spectra of films; and $(\mathrm{g})$ the tensile strength for different samples 
The pure RC film had good transparency, such that the green plant underneath could be seen. The $\mathrm{RC}-\mathrm{CaCO}_{3}$ films were not optically transparent. The transparency of $\mathrm{RC}-$ $\mathrm{CaCO}_{3}$ films decreased with increased precursor in the solutions. The green plant was almost invisible at the highest concentration of calcium carbonate. The $\mathrm{RC}-\mathrm{CaCO}_{3}$ films can be considered as a three-dimensional network structure of $\mathrm{RC}$ with micro-nano calcium carbonate particles in between. Because of the inhomogeneous structure in the surface of the composite film, as shown in the SEM image in the following section (Fig. 2), the films exhibited light scattering due to the aggregation of the precipitated calcium carbonate microcrystals (Kumar et al. 2011). The change in opacity of the $\mathrm{RC}-\mathrm{CaCO}_{3}$ films can be ascribed to the light absorption and scattering in the gaps between the cellulose fiber and the micro-nano calcium carbonate particles at the interface because the refractive indices of cellulose and $\mathrm{CaCO}_{3}$ are similar (1.56 to 1.60 vs. 1.58) (Kuo et al. 2018; Mohamadzadeh-Saghavaz et al. 2014). Translucent or almost opaque films can be achieved depending on the loading of calcium carbonate.

The DU800 UV-Vis spectrophotometer was used for quantitative analysis of the light transmittance of the films, as shown in Fig. 1f. The RC film had the highest transparency in the UV-visible region, which was above $70 \%$ transmittance. As the content of calcium carbonate increased, the transparency of films was gradually reduced in both UV and visible light range due to the light scattering (Kumar, et al. 2011).

The tensile strength of the films was measured, and the results are displayed in Fig. $1 \mathrm{~g}$. The films prepared from pure RC exhibited an average tensile strength of $76.8 \mathrm{MPa}$. It was reported that the degree of polymerization (DP) of RC did not change much after dissolution and regeneration processes, which may be responsible for the high strength (Cai et al. 2004, 2007). No obvious difference in tensile strength can be observed for the film at low calcium carbonate loading ( $\mathrm{RC}-\mathrm{C} 02)$. The tensile strength of the films was greatly enhanced by the increasing calcium carbonate loading (Choi et al. 2018; Seo et al. 2014), which had an average tensile strength of 80.5 and $84.7 \mathrm{MPa}$ for RC-05 and RC-08, respectively. Further increasing the calcium carbonate content not only did not increase the tensile strength but made it lower than the neat RC film. It was estimated that the voids of $\mathrm{RC}$ film were filled with calcium carbonate at low calcium carbonate loading, which may contribute to the tensile strength of films. However, with the further increase in calcium carbonate loading, the weak interactions between cellulose fibrils and calcium carbonate may undermine the tensile strength.

\section{SEM Morphology of RC-CaCO 3 Films}

The morphological changes of surfaces and cross-sections of the films with different calcium carbonate loading were evident from SEM images in Fig. 2. The pure RC film exhibited a fibrous network structure with a smooth surface, as shown in Figs. 2a and $2 \mathrm{a}$ '. This porous RC network structure could provide large amounts of nucleation sites for the in-situ calcium carbonate formation process. The SEM images evidenced the presence of calcium carbonate crystals within both surface and cross-section of the films. The results indicated that the crystallization of $\mathrm{CaCO}_{3}$ occurred with cellulose surrounding. The small size of visible surface crystals of precipitated calcium carbonate appeared in the RC-C02 specimen, which was prepared with the lowest concentration for in situ precipitation. The precipitated calcium carbonate with the largest size was detected in the RC-C10 film. The SEM images of the cross-section of films showed that $\mathrm{CaCO}_{3}$ filled up the network structure.

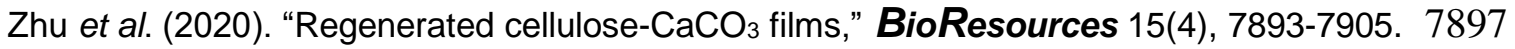



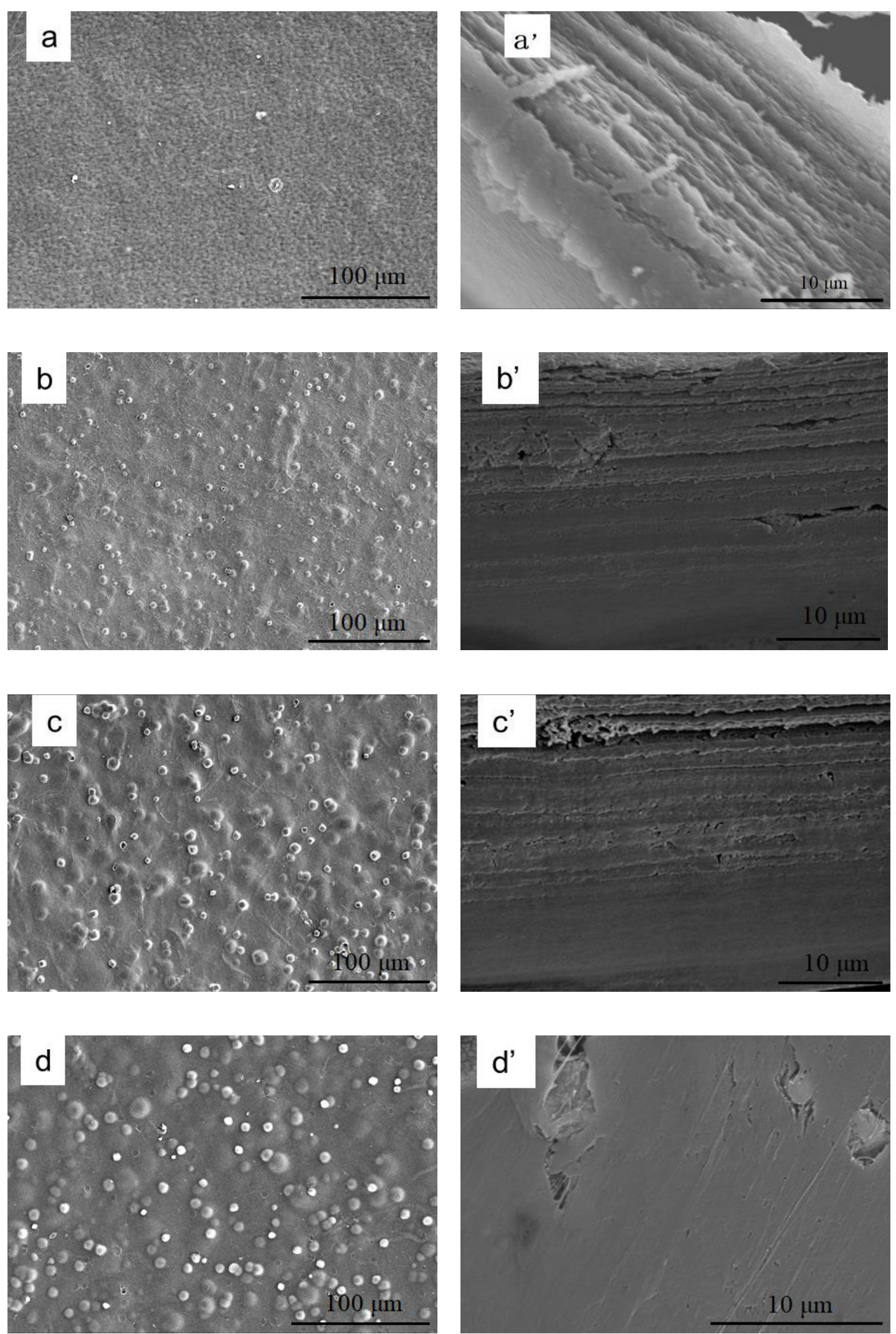

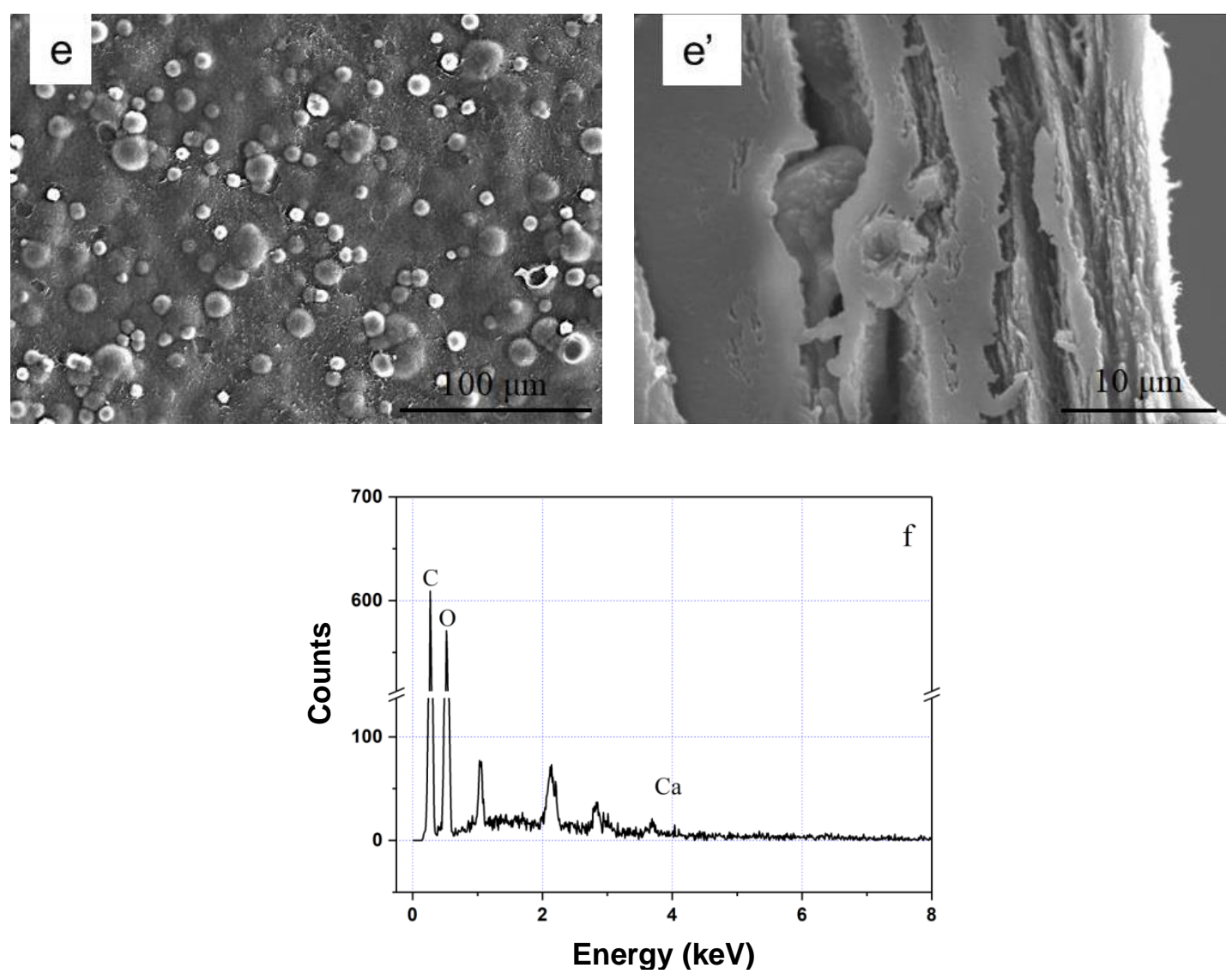

Fig. 2. SEM images of the $\mathrm{RC}-\mathrm{CaCO}_{3}$ films prepared by in situ precipitation with different concentrations of precursor solutions (a, a') RC; (b, b') RC-C02; (c, c') RC-C05; (d, d') RC-C08; (e, e') RC-C10; (f) EDS spectrum of RC-C02

Calcium carbonate particles had a smaller size and a high presence within the network pores, indicating that precipitation occurred mainly within the RC network structures. Thanks to the dense in-situ precipitation of micro-nanosized $\mathrm{CaCO}_{3}$ particles, fibrous structures could no longer be observed. It was reported that the regenerated hydrogel experienced crystallization pressure during the $\mathrm{CaCO}_{3}$ crystal growth (Rauch et al. 2012). The crystallization pressures were relatively weak compared to the strong RC network structure at a low concentration of precursor solution. When the concentration of the precursor solution was increased, the crystallization pressures pushed the RC fiber away, as shown in Figs. 2b' and 2c'. Layered structures without voids were observed in $\mathrm{RC}-\mathrm{C} 02$ and $\mathrm{RC}-\mathrm{C} 05$, which may be responsible for the high tensile strength. Further increase in the crystallization pressures resulted in the densely packed RC-C08 structure. The RC-C10 films presented large voids due to the crystallization pressure that pushed the RC network fibril away as discussed above. The collapse of the densely packed structure resulted in a decrease in tensile strength. Furthermore, as shown in Fig. $2 \mathrm{~g}$, energy dispersive X-ray spectroscopy (EDS) signals of $\mathrm{C}, \mathrm{O}$, and $\mathrm{Ca}$ elements confirmed the presence of $\mathrm{CaCO}_{3}$ in the films (Fu et al. 2014; Hafez et al. 2020).

\section{XRD Analysis of RC-CaCO 3 Films}

The incorporation of $\mathrm{CaCO}_{3}$ in the film was further recognized by the XRD pattern measurement, which is shown in Fig. 3. As a comparison, the pattern of the precipitated calcium carbonate was also supplied in which characteristic peaks corresponded to the 
structure of calcite. The XRD peaks located at $2 \theta$ values of $23.1^{\circ}, 29.6^{\circ}, 36.4^{\circ}, 39.8^{\circ}, 43.6^{\circ}$, $47.8^{\circ}$, and $48.9^{\circ}$ can be assigned to (102), (104), (110), (113), (202), (108), and (116) planes of calcite (Saraya and Rokbaa 2016). The diffraction pattern of the RC film showed three major characteristic peaks of cellulose II structure at $2 \theta=12.0^{\circ}, 20.0^{\circ}$, and $22.5^{\circ}$, which corresponded to the (1 $\overline{1}$ 0), (110), and (020) planes, respectively (Qi et al. 2009; Li et al. 2015). The XRD pattern of the RC-C05 film was quite similar to the pattern of the $\mathrm{RC}$ film. The differences between them were evident in weakened peaks at $2 \theta=20.0^{\circ}$ and $22.5^{\circ}$, corresponding to the crystalline cellulose II (110) and (020) plane, and a new peak for (104) plane of calcite (Rauch et al. 2012). The less intense and broader peaks for cellulose II in the $\mathrm{RC}-\mathrm{CaCO}_{3}$ composite indicated that the precipitated $\mathrm{CaCO}_{3}$ generated a further disordered arrangement of cellulose chains. Only the (104) plane of calcite was found in the XRD pattern. Other characteristic peaks of calcite were missing, which may be due to the low crystallinity of calcite in the composite (Niu et al. 2014; Xu et al. 2017). Overall, XRD results indicated the successful in-situ precipitation of calcite into the RC film.

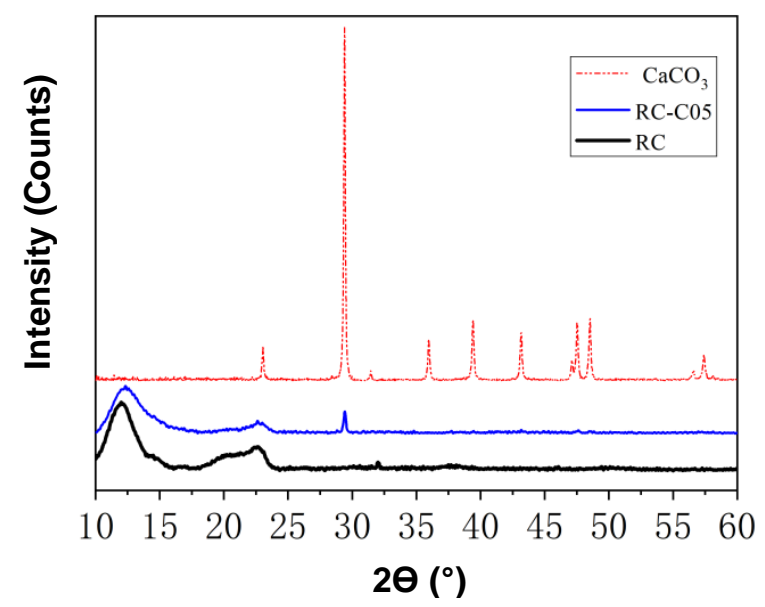

Fig. 3. X-ray diffractograms of RC film, $\mathrm{RC}-\mathrm{CO} 05$ films, and $\mathrm{CaCO}_{3}$

To gain an insight into the effect of in-situ $\mathrm{CaCO}_{3}$ precipitation on the modulation of the $\mathrm{RC}$ film structure, the precipitated $\mathrm{CaCO}_{3}$ crystal structure, $\mathrm{RC}$ film, and $\mathrm{RC}-\mathrm{CaCO}_{3}$ films were also characterized by FTIR and the spectra are shown in Fig. 4. From the FTIR spectrum of the precipitated $\mathrm{CaCO}_{3}$, it can be seen that $\mathrm{CaCO}_{3}$ had adsorption bands at 1459,875 , and $714 \mathrm{~cm}^{-1}$ corresponding to the stretching vibration of the $\mathrm{O}-\mathrm{C}-\mathrm{O}$ bond, the bending vibration in the $\mathrm{O}-\mathrm{C}-\mathrm{O}$ plane, and the out plane bending vibration, respectively. They all were characteristic peaks in the most stable polymorph of $\mathrm{CaCO}_{3}$ (calcite) (Nelson and Featherstone 1982; Swain et al. 2014).

\section{FTIR Analysis of $\mathrm{RC}-\mathrm{CaCO}_{3}$ Films}

As shown from the spectrum of pure RC film, typical characteristic peaks of cellulose were observed at 1060, 1426, 2900, and $3403 \mathrm{~cm}^{-1}$ (Wang et al. 2015). The band at $1060 \mathrm{~cm}^{-1}$ corresponded to the stretching vibration peak of the ether bond COC. The presence of the band at $1426 \mathrm{~cm}^{-1}$ was due to the shear vibration of the $-\mathrm{CH}_{2}$ group. The band at $1659 \mathrm{~cm}^{-1}$ may attributed to the $\mathrm{OH}$ bending of absorbed water. The band at 2900 $\mathrm{cm}^{-1}$ was attributed to the stretching vibration of $\mathrm{CH}$ in the $-\mathrm{CH}_{2}$ group. A wide characteristic absorption peak appearing at a position near $3403 \mathrm{~cm}^{-1}$ was the stretching vibration peak of $-\mathrm{OH}$. A moderate intensity band at $1459 \mathrm{~cm}^{-1}$, assigned to calcite, 
indicated the successful $\mathrm{CaCO}_{3}$ incorporation in the biocomposite network. Moreover, the absorption peak at $714 \mathrm{~cm}^{-1}$ also confirmed the presence of $\mathrm{CaCO}_{3}$ in the films. For RC$\mathrm{CaCO}_{3}$ films, the $-\mathrm{OH}$ peaks near $3340 \mathrm{~cm}^{-1}$ broadened and moved to the low wave direction, which may indicate the formation of new hydrogen bonding between cellulose and calcium carbonate (Ma et al. 2016).

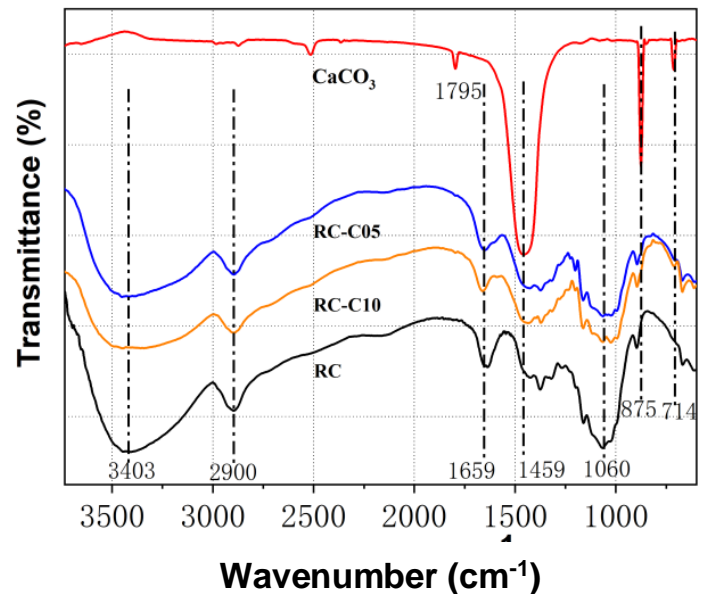

Fig. 4. $\mathrm{FTIR}$ of $\mathrm{RC}$ and $\mathrm{RC}-\mathrm{CaCO}_{3}$ films

\section{Thermal Analysis $\mathrm{RC}-\mathrm{CaCO}_{3}$ Films}

The thermal properties of $\mathrm{RC}-\mathrm{CaCO}_{3}$ were examined by TGA. The TGA results of $\mathrm{RC}$ film, $\mathrm{CaCO}_{3}$, and $\mathrm{RC}-\mathrm{CaCO}_{3}$ in the temperature range from 30 to $850{ }^{\circ} \mathrm{C}$ are compared in Fig. 5. Only one weight loss region in the range of 600 to $750{ }^{\circ} \mathrm{C}$ was observed during the decomposition of calcium carbonate. The measured value of weight left for $\mathrm{CaCO}_{3}$ after decomposition $(56.5 \%)$ was almost the same as the theoretical value $(56.1 \%)$. The TGA curve of the RC film exhibited a small weight loss in the region from room temperature to $150{ }^{\circ} \mathrm{C}$ due to the loss of moisture in the films. Following this, a two-stage degradation of RC film was located at roughly $250{ }^{\circ} \mathrm{C}$ to $380{ }^{\circ} \mathrm{C}$ and $400{ }^{\circ} \mathrm{C}$ to $700{ }^{\circ} \mathrm{C}$, respectively (Zhu et al. 2020c). The first steep decomposition region was attributed to the loss of the glycosidic bonds of cellulose, while the second stage, for the $\mathrm{RC}-\mathrm{CaCO}_{3}$ film, it was related to further degradation of cellulose and $\mathrm{CaCO}_{3}$ in the films (Jia et al. 2012; $\mathrm{Fu}$ et al. 2014). The thermal decomposition curve of $\mathrm{RC}-\mathrm{CaCO}_{3}$ displayed the same trend as that of pure RC films. However, some visible differences between the neat RC film and $\mathrm{RC}-\mathrm{CaCO}_{3}$ films in the two major decomposition regions were detected. It was noteworthy that the decomposition temperature for the $\mathrm{RC}-\mathrm{CaCO}_{3}$ film was slightly lower than that of pure RC film. The reason for TGA curve deviation may arise from the differences in the film structures and processing histories. Further studies are required to explain this early decomposition. A similar trend for the thermal degradation curve of the composite with low $\mathrm{CaCO}_{3}$ loading was also reported (Ummartyotin et al. 2016).

In the pure $\mathrm{RC}$ film, char residue was approximately $3.7 \%$ at $800{ }^{\circ} \mathrm{C}$. The $\mathrm{RC}-$ $\mathrm{CaCO}_{3}$ films presented residues of $4.6 \%, 8.8 \%$, and $12.7 \%$ for RC-C05, RC-C08, and RC$\mathrm{C} 10$, respectively, confirming the $\mathrm{CaCO}_{3}$ incorporation within the $\mathrm{RC}$ matrix. The $\mathrm{CaCO}_{3}$ content in the films could be estimated as the difference between the residue from pure RC film and $\mathrm{RC}-\mathrm{CaCO}_{3}$ films (Mohammadkazemi et al. 2016). Taking this into account, the estimated $\mathrm{CaCO}_{3}$ contents for RC-C05, RC-C08, and RC-C10 films were 1.7\%, 9.7\%, and $17.0 \%$, respectively. 


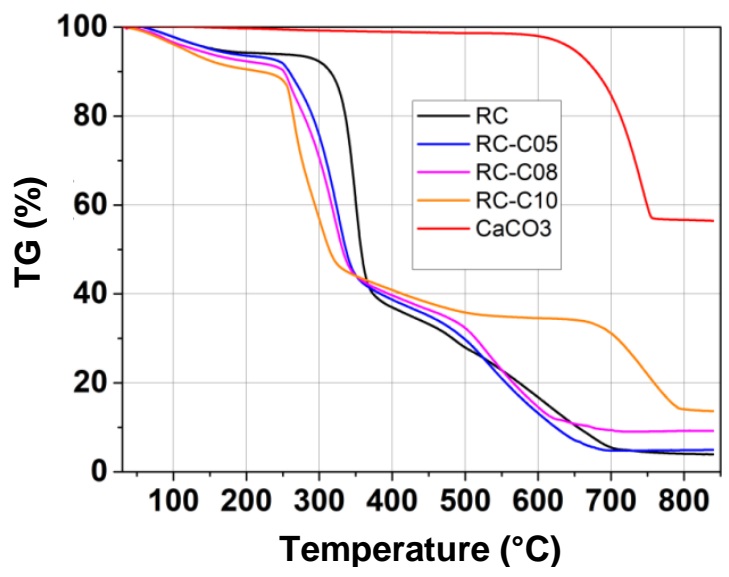

Fig. 5. TGA curves of the $\mathrm{CaCO}_{3}, \mathrm{RC}$ film, and biocomposites

\section{CONCLUSIONS}

1. Fully renewable $\mathrm{RC}-\mathrm{CaCO}_{3}$ biocomposite films were successfully synthesized by in situ precipitation of $\mathrm{CaCO}_{3}$. The results indicated that $\mathrm{CaCO}_{3}$ was successfully introduced into the RC matrix. The XRD results indicated that the most stable $\mathrm{CaCO}_{3}$ phase, calcite, was formed during in situ precipitation.

2. The properties of the biocomposite films changed as the calcium carbonate content varied. The biocomposites exhibited partial declines in transparency due to the light scattering of $\mathrm{CaCO}_{3}$ particles. The agglomerations of calcium carbonate on the surface of the films resulted in low transparency.

3. As calcium carbonate content increased, the tensile strength was first increased and then decreased. The RC-C08 film achieved the highest tensile strength of 84.7 MPa. The condensed layer structure may explain the increase in the tensile strength. The RC$\mathrm{CaCO}_{3}$ biocomposite films fabricated in this study can be regarded as a green biomaterial with large possibilities of being widely used in packaging and other applications.

\section{ACKNOWLEDGMENTS}

This work was supported by the National Key R\&D Program of China (2018YFE0107100), the State Key Laboratory of Pulp and Paper Engineering (202003), South China University of Technology, the Key Laboratory of Biomass Energy and Material of Jiangsu Province (JSBEM202012), Institute of Chemical Industry of Forest Products, Chinese Academy of Forestry, and Jiangsu University self-made experimental equipment funding (5623080004). 


\section{REFERENCES CITED}

Cai, J., Zhang, L., Zhou, J., Li, H., Chen, H., and Jin, H. (2004). "Novel fibers prepared from cellulose in $\mathrm{NaOH} / \mathrm{urea}$ aqueous solution," Macromolecular Rapid Communications 25(17), 1558-1562. DOI: 10.1002/marc.2004000172

Cai, J., Zhang, L., Zhou, J., Qi, H., Chen, H., Kondo, T., Chen, X., and Chu, B. (2007). "Multifilament fibers based on dissolution of cellulose in $\mathrm{NaOH} /$ urea aqueous solution: Structure and properties," Advanced Materials 19(6), 821-825. DOI: 10.1002/adma.200601521

Cheng, X. F., Qian, H., Zhang, S. W., Zhang, Z. S., He, Y., and Ma, M. G. (2016). "Preparation and characterization of cellulose- $\mathrm{CaCO}_{3}$ composites by an eco-friendly microwave-assisted route in a mixed solution of ionic liquid and ethylene glycol," BioResources 11(2), 4392-4401. DOI: 10.15376/biores.11.2.4392-4401

Choi, J. S., Kang, D. S., Han, J. S., and Seo, Y. B. (2018). "Property development mechanism of hybrid calcium carbonate," ACS Sustainable Chemistry \& Engineering 7(1), 1538-1544. DOI: 10.1021/acssuschemeng.8b05304

Ciobanu, M., Bobu, E., and Ciolacu, F. (2010). "In-situ cellulose fibres loading with calcium carbonate precipitated by different methods," Cellulose Chemistry and Technology 44(9), 379-387.

Delhom, C. D., White-Ghoorahoo, L. A., and Pang, S. S. (2010). "Development and characterization of cellulose/clay nanocomposites," Composites Part B: Engineering 41(6), 475-481. DOI: 10.1016/j.compositesb.2009.10.007

Fu, L. H., Ma, M.-G., Bian, J., Deng, F., and Du, X. (2014). "Research on the formation mechanism of composites from lignocelluloses and $\mathrm{CaCO}_{3}$," Materials Science and Engineering: $C$ 44, 216-224. DOI: 10.1016/j.msec.2014.08.029

Hafez, I., Amini, E., and Tajvidi, M. (2020). "The synergy between cellulose nanofibrils and calcium carbonate in a hybrid composite system," Cellulose 27(7), 3773-3787. DOI: $10.1007 / \mathrm{s} 10570-020-03032-\mathrm{w}$

Jia, N., Li, S. M., Ma, M. G., Sun, R. C., and Zhu, J. F. (2012). "Hydrothermal fabrication, characterization, and biological activity of cellulose/ $\mathrm{CaCO}_{3}$ bionanocomposites," Carbohydrate Polymers 88(1), 179-184. DOI: 10.1016/j.carbpol.2011.11.086

Kumar, N., Bhardwaj, N. K., and Chakrabarti, S. K. (2011). "Influence of particle size distribution of calcium carbonate pigments on coated paper whiteness," Journal of Coatings Technology and Research 8(5), Article number 613. DOI: 10.1007/s11998011-9353-y

Kuo, D., Nishimura, T., Kajiyama, S., and Kato, T. (2018). "Bioinspired environmentally friendly amorphous $\mathrm{CaCO}_{3}$-based transparent composites comprising cellulose nanofibers," ACS Omega 3(10), 12722-12729. DOI: 10.1021/acsomega.8b02014

Laukala, T., Kronlund, D., Heiskanen, I., and Backfolk, K. (2017). "The effect of polyacrylic acid and reaction conditions on nanocluster formation of precipitated calcium carbonate on microcellulose," Cellulose 24(7), 2813-2826. DOI: $10.1007 / \mathrm{s} 10570-017-1296-8$

Li, R., Wang, S., Lu, A., and Zhang, L. (2015). "Dissolution of cellulose from different sources in an $\mathrm{NaOH} /$ urea aqueous system at low temperature," Cellulose 22(1), 1-11. DOI: $10.1007 / \mathrm{s} 10570-014-0542-6$ 
Ma, M. G., Liu, S., and Fu, L. H. (2016). "Calcium carbonate and cellulose/calcium carbonate composites: Synthesis, characterization, and biomedical applications," Materials Science Forum 875, 24-44. DOI: 10.4028/www.scientific.net/MSF.875.24

Mohamadzadeh-Saghavaz, K., Resalati, H., and Ghasemian, A. (2014). "Celluloseprecipitated calcium carbonate composites and their effect on paper properties," Chemical Papers 68(6), 774-781. DOI: 10.2478/s11696-013-0513-7

Mohammadkazemi, F., Faria, M., and Cordeiro, N. (2016). "In situ biosynthesis of bacterial nanocellulose- $\mathrm{CaCO}_{3}$ hybrid bionanocomposite: One-step process," Materials Science and Engineering: C 65, 393-399. DOI:

10.1016/j.msec.2016.04.069

Nakao, Y., Sugimura, K., and Nishio, Y. (2019). " $\mathrm{CaCO}_{3}$ mineralization in polymer composites with cellulose nanocrystals providing a chiral nematic mesomorphic structure," International Journal of Biological Macromolecules 141, 783-791. DOI: 10.1016/j.ijbiomac.2019.09.045

Nelson, D., and Featherstone, J. (1982). "Preparation, analysis, and characterization of carbonated apatites," Calcified Tissue International 34, S69-81.

Niu, T., Xu, J., and Huang, J. (2014). "Growth of aragonite phase calcium carbonate on the surface of a titania-modified filter paper," CrystEngComm 16(12), 2424-2431. DOI: $10.1039 / \mathrm{c} 3 \mathrm{ce} 42322 \mathrm{k}$

Qi, H., Cai, J., Zhang, L., and Kuga, S. (2009). "Properties of films composed of cellulose nanowhiskers and a cellulose matrix regenerated from alkali/urea solution," Biomacromolecules 10(6), 1597-1602. DOI: 10.1021/bm9001975

Rauch, M. W., Dressler, M., Scheel, H., Van Opdenbosch, D., and Zollfrank, C. (2012). "Mineralization of calcium carbonates in cellulose gel membranes," European Journal of Inorganic Chemistry 2012(32), 5192-5198. DOI: 10.1002/ejic.201200575

Saito, T., Oaki, Y., Nishimura, T., Isogai, A., and Kato, T. (2014). "Bioinspired stiff and flexible composites of nanocellulose-reinforced amorphous $\mathrm{CaCO}_{3}$," Materials Horizons 1(3), 321-325. DOI: 10.1039/c3mh00134b

Saraya, M. E. S. I., and Rokbaa, H. (2016). "Preparation of vaterite calcium carbonate in the form of spherical nano-size particles with the aid of polycarboxylate superplasticizer as a capping agent," American Journal of Nanomaterials 4(2), 44-51. DOI: 10.12691/ajn-4-2-3

Sathitsuksanoh, N., George, A., and Zhang, Y. H. P. (2013). "New lignocellulose pretreatments using cellulose solvents: A review," Journal of Chemical Technology and Biotechnology 88(2), 169-180. DOI: 10.1002/jctb.3959

Seo, Y. B., Ahn, J. H., and Lee, H. L. (2017). "Upgrading waste paper by in-situ calcium carbonate formation," Journal of Cleaner Production 155(Part 1), 212-217. DOI: 10.1016/j.jclepro.2016.09.003

Seo, Y. B., Lee, Y. H., and Chung, J. K. (2014). "The improvement of recycled newsprint properties by in-situ $\mathrm{CaCO}_{3}$ loading," BioResources 9(4), 6254-6266. DOI: 10.15376/biores.9.4.6254-6266

Swain, S. K., Dash, S., Kisku, S. K., and Singh, R. K. (2014). “Thermal and oxygen barrier properties of chitosan bionanocomposites by reinforcement of calcium carbonate nanopowder," Journal of Materials Science \& Technology 30(8), 791-795. DOI: 10.1016/j.jmst.2013.12.017

Ummartyotin, S., Pisitsak, P., and Pechyen, C. (2016). "Eggshell and bacterial cellulose composite membrane as absorbent material in active packaging," International Journal of Polymer Science 2016, Article ID 1047606. DOI: 10.1155/2016/1047606 
Wang, Q., Wei, W., Kingori, G. P., and Sun, J. (2015). "Cell wall disruption in low temperature $\mathrm{NaOH} /$ urea solution and its potential application in lignocellulose pretreatment," Cellulose 22(6), 3559-3568. DOI: 10.1007/s10570-015-0767-z

Wang, Q., Wei, W., Li, X., Sun, J., He, J., and He, M. (2016). "Comparative study of alkali and acidic cellulose solvent pretreatment of corn stover for fermentable sugar production," BioResources 11(1), 482-491. DOI: 10.15376/biores.11.1.482-491

Wang, Q., Yao, Q., Liu, J., Sun, J., Zhu, Q., and Chen, H. (2019). “Processing nanocellulose to bulk materials: A review," Cellulose 26(13-14), 7585-7617. DOI: 10.1007/s10570-019-02642-3

Wang, Q. Q., Sun, J. Z., Yao, Q., Ji, C. C., Liu, J., and Zhu, Q. Q. (2018). “3D printing with cellulose materials," Cellulose 25(8), 4275-4301. DOI: 10.1007/s10570-018$1888-y$

Xiao, W., Liu, J., Chen, Q., Wu, Y., Dai, L., and Wu, T. (2011). “Controllable mineralization of calcium carbonate on regenerated cellulose fibers," Crystal Research and Technology 46(10), 1071-1078. DOI: 10.1002/crat.201100261

Xu, Y. J., Jiang, C. M., Duan, C., and Zhang, W. P. (2017). "In-situ preparation of nanocalcium carbonate/cellulose fiber composite and its application in fluff pulp," Journal of Engineered Fibers and Fabrics 12(3), 48-53. DOI: 10.1177/155892501701200306

Yang, Q., Wu, C. N., Saito, T., and Isogai, A. (2014). 'Cellulose-clay layered nanocomposite films fabricated from aqueous cellulose/LiOH/urea solution," Carbohydrate Polymers 100, 179-184. DOI: 10.1016/j.carbpol.2012.10.044

Zhu, Q., Liu, S., Sun, J., Liu, J., Kirubaharan, C. J., Chen, H., Xu, W., and Wang, Q. (2020a). "Stimuli-responsive cellulose nanomaterials for smart applications," Carbohydrate Polymers 235, Article ID 115933. DOI:

10.1016/j.carbpol.2020.115933

Zhu, Q., Wang, J., Sun, J., and Wang, Q. (2020b). "Preparation, characterization, and oxygen barrier properties of regenerated cellulose/polyvinyl alcohol blend films," BioResources 15(2), 2735-2746. DOI: 10.15376/biores.15.2.2735-2746

Zhu, Q., Yao, Q., Sun, J., Chen, H., Xu, W., Liu, J., and Wang, Q. (2020c). "Stimuli induced cellulose nanomaterials alignment and its emerging applications: A review," Carbohydrate Polymers 230, Article ID 115609. DOI: 10.1016/j.carbpol.2019.115609

Article submitted: June 20, 2020; Peer review completed: August 15, 2020; Revised version received: August 17, 2020; Accepted: August 18, 2020; Published: August 31, 2020.

DOI: $10.15376 /$ biores. 15.4.7893-7905 